\title{
Escala de forças de caráter: evidências de validade no contexto da orientação para a carreira
}

\section{Character strengths scale: evidence of validity in the context of career guidance}

\author{
Lara Priscila de Campos (orcid.org/0000-0002-1151-2170)' \\ Rodolfo Augusto Matteo Ambiel (orcid.org/0000-0002-3921-8547)2 \\ Gustavo Henrique Martins (orcid.org/0000-0002-5125-2553) ${ }^{3}$
}

\begin{abstract}
Resumo
Esta pesquisa teve como objetivo encontrar evidências de validade para a escala de forças de caráter (EFC), correlacionando-a com a escala de adaptabilidade de carreira (EAC) baseada na relação com variáveis externas, ou seja, entre os escores dos instrumentos a serem utilizados, e outras variáveis como idade, sexo e situação laboral. Participaram por meio de pesquisa on-line 364 respondentes com idade entre 18 e 77 anos. Uma importante contribuição desta pesquisa foi o que se constatou quanto à situação laboral, sugerindo que a capacidade de inovar e estar aberto a novas experiências são fundamentais para aqueles que desejam se manter empregados. Os resultados também inferem que as pessoas mais jovens costumam pensar mais sobre seu futuro profissional do que as pessoas mais velhas, porém, a maturidade associada a um maior nível de conhecimento (escolaridade) promove uma maior pontuação entre as forças de caráter.
\end{abstract}

Palavras-chave: Psicologia positiva. Forças de caráter. Orientação de carreira. Adaptabilidade de carreira.

\begin{abstract}
This research aimed to find evidence of validity for the character strengths scale (CSS), correlating it with the career adapt-abilities scale (CAAS) based on the relationship with external variables, that is, between the scores of the instruments to be used, and other variables such as age, sex and employment situation. A total of 364 respondents aged between 18 and 77 years old participated in an online survey. An important contribution of this research was regarding the employment situation, suggesting that the ability to innovate and be open to new experiences are fundamental for those who wish to remain employed. The results also infer that younger people tend to think more
\end{abstract}

\footnotetext{
${ }^{1}$ Universidade São Francisco, Bragança Paulista, Brasil. E-mail: lara@laracampos.com.br.

${ }^{2}$ Universidade São Francisco, Bragança Paulista, Brasil. E-mail: ambielram@gmail.com.

${ }^{3}$ Universidade São Francisco, Bragança Paulista, Brasil. E-mail: gustavoh.martins95@gmail.com.
} 
about their professional future than older people; however, the maturity associated with a higher level of knowledge (education) promotes a higher score among the strength of character.

Keywords: Positive psychology. Strength of character. Career guidance. Career adaptability.

Ao pesquisarem sobre o cenário pós-guerra, os psicólogos Seligman e Csikszentmihalyi (2000) observaram que muitos indivíduos bem-sucedidos e autoconfiantes se mostraram desencorajados em relação à crítica situação global. Notaram também que, em contrapartida, mesmo sem o suporte social pós-guerra, havia alguns poucos sobreviventes que conseguiam manter sua integridade e propósitos e, ainda, que eles não eram pessoas com maior prestígio social, nem com o maior grau de escolaridade ou os mais dotados de habilidades individuais. Diante desse contexto, os autores se questionavam de quais fontes possivelmente essas pessoas estariam extraindo forças e, assim, a partir dessa inquietação, começaria a surgir o movimento da Psicologia Positiva, com o propósito de potencializar os traços positivos dos indivíduos e ajudá-los a encontrar felicidade e bemestar (Seligman \& Csikszentmihalyi, 2000).

No início da década de 2000, foi lançado um manual de sanidades que descreve o que há de virtuoso nos seres humanos (Peterson \& Seligman, 2004). O projeto intitulado The Values in Action (VIA), em português Valores em Ação, dos autores Park, Peterson e Seligman (Peterson \& Seligman, 2004; Park \& Peterson, 2009) é o ponto de partida do estudo científico sistemático que mensura e classifica as forças de caráter. O manual Values in Action (VIA) Classification of Strenghts, em português Valores em Ação, Classificação das Forças, descreve seis grandes virtudes (Sabedoria e Conhecimento, Coragem, Humanidade, Justiça, Temperança e Transcendência) que estão subdivididas em 24 forças de caráter (Pensamentos Crítico, Criatividade, Curiosidade, Amor ao Aprendizado, Sensatez, Bravura, Perseverança, Autenticidade, Vitalidade, Amor, Bondade, Inteligência Social, Cidadania, Liderança, Imparcialidade, Autorregulação, Modéstia, Perdão, Prudência, Espiritualidade, Apreço ao Belo, Humor, Gratidão e Esperança).

As forças de caráter, elementos que definem as virtudes, são descritas como aspectos da personalidade moralmente valorizados, ou seja, traços positivos bem 
desenvolvidos e elementos fundamentais para manter o bem-estar da sociedade e prevenila de patologias que surgem normalmente devido à exposição ao estresse gerado pelos problemas do dia a dia. Ter esses traços positivos bem desenvolvidos não significa ter ausência de problemas, mas uma capacidade maior de enfrentá-los. Entende-se que essas forças são influenciadas por uma combinação de fatores que vão desde a família, escola, cônjuge, comunidade até a hereditariedade e, em vez de serem avaliadas por presença ou ausência, são passíveis de avaliação em graus, ou seja, os pensamentos, sentimentos e ações do indivíduo podem expressar as forças em graus fraco, moderado ou forte, por exemplo (Peterson \& Seligman, 2004).

Park e Peterson (2009) consideram que as forças de caráter, como a Esperança, Bondade, Inteligência Social, Autorregulação e Sensatez amenizam os efeitos negativos do estresse e traumas, prevenindo e/ou minimizando problemas. Elas também ajudam jovens adultos a prosperar e estão associadas a competências muito desejadas, como a de se ter sucesso escolar, liderança, tolerância, saber trabalhar com a diversidade e habilidade de adiar a gratificação imediata. Seligman (2003) observa que as forças de caráter servem como fatores protetivos, uma vez que se estas estiverem presentes nas pessoas haverá diminuição de doenças e consequentemente uma melhora na qualidade de vida.

Uma pesquisa realizada em 54 países, incluindo o Brasil, revela as forças de caráter mais e menos destacadas. As mais destacadas foram Bondade, Imparcialidade, Autenticidade, Gratidão, Pensamento Crítico, Amor, e Humor. As menos destacadas foram Prudência, Modéstia e Autorregulação (Park et al., 2006). No Brasil, Noronha e Barbosa (2016), com base no modelo VIA, desenvolveram a Escala de Forças de Caráter (EFC), com o objetivo de analisar as forças em amostras brasileiras. Para a realização do estudo, foram examinados 1.423 estudantes do ensino médio e superior. As forças mais evidentes na amostra foram Gratidão, Curiosidade e Esperança e, em contrapartida, a força com menor média foi Perdão.

A pesquisa também avaliou a diferença entre os sexos. Os resultados indicaram no sexo masculino uma maior pontuação em Pensamento Crítico, Autorregulação e Perseverança. Nas mulheres, o estudo apontou maior pontuação em Autenticidade, 
Bondade, Amor, Inteligência Social, Modéstia, Apreciação ao Belo e Espiritualidade. Outra variável analisada foi a idade. Os participantes foram divididos em três grupos: o primeiro reuniu jovens com menos de 18 anos; o segundo pessoas com idades entre 18 e 22 anos; e o terceiro pessoas com mais de 22 anos. Os resultados mostraram que os participantes mais jovens, com menos de 18 anos, tiveram médias maiores em Bravura, Inteligência Social e Modéstia. Os participantes acima de 22 anos apresentaram médias maiores em Pensamento Crítico, Amor pelo Aprendizado, Amor, Imparcialidade, Liderança, Cidadania, Autorregulacão, Apreciação do Belo, Gratidão e Espiritualidade (Noronha \& Barbosa, 2016).

Como resultado do movimento da Psicologia Positiva, novas áreas de pesquisa manifestam-se também no comportamento das organizações. Desde os primeiros estudos iniciados por Elton Mayo em 1927, na Western Eletric Company, o Comportamento Organizacional (CO) tem mostrado uma clara relação entre sentimentos positivos dos funcionários e seus melhores desempenhos (Luthans, 2002). Em 2003, por exemplo, surge o conceito Organizações Positivas, com o objetivo de compreender os resultados organizacionais com foco no desempenho positivo das pessoas (Cameron, Dutton \& Quinn, 2003). Segundo Cameron e Spreitzer (2003), as Organizações Positivas investigam o que há de certo com elas e com as pessoas, suas forças e virtudes e os relacionamentos positivos.

Outra área da Psicologia que também estuda as virtudes e forças do indivíduo é a Orientação Profissional (OP), que, de acordo com Savickas (1999), tem o objetivo de orientar as pessoas em suas carreiras, compreender melhor as características das profissões, proporcionando assim autoconhecimento e o despertar de potencialidades até então desconhecidas. Savickas (2002) define carreira como uma construção subjetiva que exige a obtenção de significado pessoal mediante memórias passadas, experiências presentes, e aspirações futuras, moldando ou emoldurando, assim, o tema de vida de um indivíduo. A Teoria de Construção de Carreira (TCC) do autor se modifica com a visão de carreira como sendo algo sequencial, isto é, vários empregos ao longo da vida ou inúmeras promoções em uma mesma empresa. Ainda, a teoria propõe ser um processo subjetivo e ativo, que ajuda indivíduos a criar significado e maior relevância em suas tarefas profissionais diárias, a 
encontrar melhores caminhos, a colocar em prática suas próprias ideias e anseios e a avançar em seus projetos, a despeito de qualquer experiência passada e barreiras sociais.

Um elemento central da Teoria de Construção de Carreira de Savickas (2005) é a adaptabilidade, que trata de um construto psicossocial que representa os recursos de um indivíduo para lidar com as necessidades atuais, previstas, tarefas, transições e traumas em seus papéis ocupacionais, que em algum grau, alteram sua integração social (Savickas \& Porfeli, 2012). A adaptabilidade de carreira está mais associada a como o indivíduo vem construindo sua trajetória profissional do que com qual ocupação ele se interessa, sugerindo uma evolução da abordagem de desenvolvimento de carreira concebida pelo seu precursor.

Como parte de suas contribuições, Savickas $(2005,2013)$ desenvolveu quatro dimensões de adaptabilidade de carreira, as quais representam competências comportamentais ou estratégias adaptativas utilizadas por indivíduos que conseguem se adaptar, administrar as tarefas críticas, traumas e transições enquanto constroem suas carreiras. As dimensões são conhecidas como os $4 \mathrm{Cs}$, originalmente em inglês intituladas Concern, Control, Curiosity e Confidence, e traduzidas para o português, respectivamente, como Preocupação, significando, em sua essência, a competência de orientação para o futuro, um senso de responsabilidade para se preparar para o amanhã; Controle, sugerindo responsabilidade incondicional por criar sua própria história ou trajetória profissional e ainda, o quanto os indivíduos sentem e acreditam que eles próprios são os responsáveis pela construção de suas carreiras; Curiosidade, que corresponde ao interesse de aprender, explorar ou experienciar novas tarefas e caminhos profissionais; e Confiança, que corresponde à capacidade de acreditar em si mesmo para superar obstáculos, resolver problemas e atingir objetivos.

Uma análise feita por Johnston, Luciano, Maggiori, Ruch, e Rossier (2013) identificou a correlação positiva entre adaptabilidade de carreira e orientações para a felicidade. Também reconheceu que as orientações para a felicidade incluem três aspectos positivos, sendo o primeiro aspecto considerado de engajamento, que descreve o estado de fluxo e que está diretamente relacionado à capacidade de ajuste entre os desafios e/ou demandas 
exigidas e as competências do indivíduo. O segundo aspecto positivo trata da satisfação, que descreve a tendência a se maximizar o prazer e minimizar o sofrimento; e o terceiro aspecto trata do significado, que descreve a identificação dos indivíduos com suas virtudes e a contribuição destas para com sua identidade. Os autores observaram que esses três traços positivos estavam relacionados à adaptabilidade de carreira.

Nessa mesma perspectiva, outras pesquisas têm associado positivamente a adaptabilidade de carreira à autoestima (Van Vianen, Klehe, Koen \& Dries, 2012), ao sucesso na carreira, alta performance e bem-estar (Maggiori, Johnston, Krings, Massaoudi \& Rossier, 2013; Ohme \& Zacher, 2015). Ainda, a adaptabilidade de carreira apresenta uma correlação negativa com o medo e o fracasso (Pouyaud, Vignoli, Dosnon \& Lallemand, 2012), com o estresse no trabalho e pode ser considerada como um fator protetivo ao burnout (Browning, Ryan, Greenberg \& Rolniak, 2006; Johnston, Broonen et al., 2013; Johnston, Luciano et al., 2013).

Um estudo realizado por Buyukgoze-Kavas (2015) indicou que esperança, resiliência e otimismo foram preditores positivos da adaptabilidade de carreira, explicando, juntos, um total de $48 \%$ de adaptabilidade. A esperança também tem sido positivamente correlacionada com planejamento e decisividade de carreira (Hirschi, 2014) e adaptabilidade diante de situações de estresse (Snyder, 2002). Wanberg e Banas (2000) identificaram que empregados com características da resiliência são mais adaptáveis às mudanças organizacionais, e que níveis mais baixos de aceitação às mudanças estão associados a uma menor satisfação no trabalho, irritação e forte tendência ao desligamento. Os autores ainda afirmam que indivíduos com maior nível de bem-estar durante eventos estressantes são aqueles que têm alto nível de autoestima, otimismo e controle pessoal.

Por sua vez, um estudo indicou que as forças de caráter são correlacionadas positivamente com variáveis de desempenho profissional, como sentido de trabalho, engajamento, satisfação no trabalho, desempenho no trabalho, comportamento de cidadania organizacional, e negativamente correlacionadas com comportamentos contraprodutivos no trabalho (Littman-Ovadia, Lavy \& Boiman-Meshita, 2017). Nesse 
sentido, a literatura demonstra que a adaptabilidade de carreira se relaciona positivamente com variáveis da Psicologia Positiva, ao passo que as forças de caráter se relacionam positivamente com variáveis positivas de carreira. Entretanto pouco se sabe sobre a relação direta entre ambos os construtos.

Diante do exposto e presumindo-se ser a adaptabilidade de carreira e as forças de caráter recursos importantes ao profissional do século XXI, esta pesquisa teve como objeto de estudo esses dois construtos contemporâneos e ainda pouco explorados no Brasil, no intuito de encontrar evidências de validade para a Escala de Forças de Caráter (Noronha \& Barbosa, 2016), baseada na relação com variáveis externas, ou seja, entre os escores dos instrumentos a serem utilizados, e outras variáveis como idade, sexo, situação laboral e escolaridade. Como hipóteses do estudo, espera-se encontrar correlações positivas entre a dimensão Preocupação com as forças Pensamento Crítico, Vitalidade, Prudência e Espiritualidade; entre a dimensão Controle com as forças Vitalidade e Autorregulação; entre Curiosidade com Criatividade, Curiosidade e Amor ao Aprendizado; e entre a dimensão Confiança com as forças Bravura, Perseverança, Autenticidade, Vitalidade e Esperança.

\section{Método}

\section{Participantes}

A amostra deste estudo foi composta por 364 participantes, em sua maioria do sexo feminino (64\%), graduados (36,5\%) e pós-graduados $(46,10 \%)$ e com idade mínima de 18 e máxima de 77 anos. Quanto à situação laboral, 59 (16,2\%) respondentes estavam desempregados, 13 (3,6\%) estavam trabalhando há menos de seis meses e 265 (72,8\%) há mais de seis meses. Quanto ao grau de escolaridade, a maioria apresentou formação superior, sendo que 133 (36,5\%) tinham a graduação completa; 111 (30,5\%), especialização; $46(12,6 \%)$ mestrado; e 11 (3,0\%), doutorado. 


\section{Instrumentos}

Foi utilizado um questionário sociodemográfico com o objetivo de identificar e selecionar os participantes. Também foram aplicadas duas escalas: a Escala de Forças de Caráter(EFC), desenvolvida para o contexto brasileiro por Noronha e Barbosa (2016) e baseada no modelo de Peterson e Seligman (2004). A versão final dessa escala foi composta por 71 itens no formato Likert ( 0 para nada a ver comigo e 4 para tudo a ver comigo); e a Escala de Adaptabilidade de Carreira (EAC), também conhecida internacionalmente como Career Adapt-Abilities Scale (CAAS), desenvolvida e adaptada ao contexto brasileiro e baseada no modelo português de Duarte et al. (2012); Teixeira, Bardagi, Lassance, Magalhães e Duarte (2012). Essa versão é composta por 24 itens no formato Likert (1 para desenvolvi pouco ou nada e 5 para desenvolvi extremamente bem).

\section{Procedimentos}

Após aprovação do Comitê de Ética (CAAE 61155516.0 .0000 .5514$)$, foram utilizadas duas estratégias para a coleta de dados: a primeira foi contatar os possíveis participantes do estudo por meio de redes sociais, Facebook/Linkedin, sendo os convites disponibilizados para os respectivos grupos de interesse pela temática do estudo; a segunda estratégia de captação foi a aplicação da técnica denominada de snow ball sampling, ou amostragem de bola de neve (Van Meter, 1990), na qual se solicita aos participantes que encaminhem a pesquisa também a seus colegas de trabalho, parentes e amigos. Um convite eletrônico foi enviado aos participantes pelo site Google Forms, que ficou disponível durante 30 dias.

\section{Análise de dados}

Para a descrição dos participantes, foram utilizadas estatísticas descritivas, especialmente frequências, média e desvio padrão. Para os resultados, foi utilizado o coeficiente de correlação $r$ de Pearson para medir a tendência e magnitude da correlação 
entre os fatores dos dois instrumentos; e o teste $t$ de Student para a comparação dos grupos entre empregados e desempregados, homens e mulheres e graduados e não graduados. Também foi utilizado o teste paramétrico ANOVA (Análise de Variância) para verificar diferenças das médias entre três ou mais categorias de grupos. Para interpretar as magnitudes das correlações, serão seguidos os critérios apresentados por Cohen (1992), o qual aponta que correlações com $r=0,20$ são fracas, $r=0,30$ são moderadas e $r=0,50$ são fortes.

\section{Resultados}

Inicialmente, buscou-se verificar as correlações entre as forças da EFC e os fatores da EAC. Para melhor visualização, as 24 forças foram organizadas por virtudes. A seguir, na Tabela 1, serão descritas as correlações de Pearson entre os instrumentos.

Tabela 1. Correlações entre as forças de caráter, organizadas por virtudes e os fatores de adaptabilidade de carreira

\begin{tabular}{lcccc}
\hline \multicolumn{1}{c}{ EFC/EAC } & Preocupação & Controle & Curiosidade & Confiança \\
\hline \multicolumn{1}{c}{ Escore total } & $\mathbf{0 , 4 0}$ & $\mathbf{0 , 5 4}$ & $\mathbf{0 , 4 7}$ & $\mathbf{0 , 5 8}$ \\
\hline \multicolumn{1}{c}{ Sabedoria e conhecimento } & & & & \\
\hline Pensamento crítico & 0,41 & 0,49 & 0,53 & 0,50 \\
Criatividade & 0,28 & 0,40 & 0,45 & 0,40 \\
Curiosidade & 0,38 & 0,46 & 0,53 & 0,54 \\
Amor ao aprendizado & 0,35 & 0,48 & 0,53 & 0,59 \\
Sensatez & 0,35 & 0,35 & 0,35 & 0,43 \\
\hline \multicolumn{1}{c}{ Coragem } & & & & \\
\hline Bravura & 0,23 & 0,37 & 0,34 & 0,41 \\
Perseverança & 0,46 & 0,52 & 0,46 & 0,58 \\
Autenticidade & 0,28 & 0,42 & 0,32 & 0,44 \\
Vitalidade & 0,31 & 0,42 & 0,35 & 0,45 \\
\hline
\end{tabular}

\section{Humanidade}




\begin{tabular}{lllll}
\hline Amor & 0,21 & 0,31 & 0,18 & 0,28 \\
Bondade & 0,21 & 0,36 & 0,24 & 0,38 \\
Inteligência social & 0,26 & 0,33 & 0,26 & 0,30 \\
\hline \multicolumn{1}{c}{ Justiça } & & & & \\
\hline Cidadania & 0,35 & 0,40 & 0,37 & 0,44 \\
Liderança & 0,33 & 0,40 & 0,35 & 0,48 \\
Imparcialidade & 0,27 & 0,43 & 0,34 & 0,50 \\
\hline \multicolumn{1}{c}{ Temperança } & & & & \\
\hline Autorregulação & 0,24 & 0,25 & 0,27 & 0,34 \\
Modéstia & 0,26 & 0,31 & 0,25 & 0,37 \\
Perdão & 0,09 & 0,20 & 0,12 & 0,20 \\
Prudência & 0,34 & 0,35 & 0,40 & 0,41 \\
\hline \multicolumn{1}{c}{ Transcendência } & & & & \\
\hline Espiritualidade & 0,16 & 0,30 & 0,20 & 0,27 \\
Apreciação a beleza & 0,30 & 0,41 & 0,30 & 0,38 \\
Humor & 0,29 & 0,33 & 0,29 & 0,36 \\
Gratidão & 0,30 & 0,41 & 0,29 & 0,40 \\
Esperança & 0,31 & 0,45 & 0,31 & 0,42 \\
\hline Nota: Todas as correlaçôn & & 0,30 & \\
\hline
\end{tabular}

Nota: Todas as correlações foram significativas em nível de $p \leq 0,001$.

Fonte: Elaborada pelos autores.

Conforme observado na Tabela 1, os dois construtos abordados neste estudo se correlacionaram positivamente, com magnitudes variando de fracas a fortes. Entre as cinco forças componentes da virtude Sabedoria e Conhecimento, a que se destaca é a força Amor ao Aprendizado como a mais fortemente correlacionada ao fator Confiança e, ainda, esta também se destaca devido à maior magnitude entre as 24 forças. As forças Pensamento Crítico e Criatividade estão mais correlacionadas ao fator Curiosidade, e as forças Curiosidade, Amor ao Aprendizado e Sensatez correlacionaram-se mais ao fator Confiança.

Entre as quatro forças relacionadas à virtude Coragem, a que se destaca é a força Perseverança, sendo que, mais especificamente, esta também se destaca por apresentar a 
segunda maior magnitude entre as 24 forças. Todas as quatro forças Bravura, Perseverança, Autenticidade e Vitalidade correlacionaram-se mais também ao fator Confiança. Ainda, mesmo não esperando encontrar correlações positivas mais evidentes, das três forças relacionadas à virtude Humanidade, duas (Amor e Inteligência Social) correlacionaram-se mais fortemente ao fator Controle e uma (Bondade) correlacionou-se ao fator Confiança, assim como das três forças relacionadas à virtude Justiça também todas estão correlacionadas mais fortemente ao fator Confiança.

Analisando as forças abarcadas na virtude Temperança, todas se correlacionaram mais fortemente ao fator Confiança. A força Perdão correlacionou-se da mesma forma ao fator Controle, mas em ambos os casos a magnitude foi fraca, sendo estas nulas com os demais fatores da EAC. Entre as cinco forças relacionadas à virtude Transcendência, quatro (Espiritualidade, Apreciação a Beleza, Gratidão e Esperança) se correlacionaram também mais fortemente ao fator Controle e uma força (Humor) se relacionou ao fator Confiança.

Em resumo, o que se destaca na Tabela 1 é que a maioria das forças de caráter, 16 mais especificamente (Curiosidade, Amor ao Aprendizado, Sensatez, Bravura, Perseverança, Autenticidade, Vitalidade, Bondade, Cidadania, Liderança, Imparcialidade, Autorregulação, Modéstia, Perdão, Prudência e Humor), se correlacionou mais fortemente ao fator Confiança da EAC, sendo esse o fator da EAC mais correlacionado ao escore total da EFC.

Em seguida, foram comparadas as médias dos escores dos instrumentos em função dos grupos especificados em sexo, situação laboral, faixa etária e escolaridade, sendo que para sexo e situação laboral foram realizados teste $t$ e para os demais ANOVA. Na situação laboral, foram considerados os empregados $(n=265)$ e desempregados $(n=59)$, com seis meses ou mais de experiência no mercado e trabalho. Não houve diferenças significativas para nenhum dos fatores da EAC em relação aos grupos formados pelo sexo. Apenas as forças de caráter Autenticidade e Humor foram consideradas significativas em relação aos grupos formados pelo sexo masculino $(n=131)$ e feminino $(n=233)$. Esse último apresentou maior média na força de caráter Autenticidade, em comparação com o grupo formado pelo sexo masculino (feminino: $M=3,06$; $D P=0,70$; masculino: $M=2,86$; $D P=$ $0,77 ; t=2,04 ; p=0,04)$. Por outro lado, em relação à força Humor, observou-se que o 
grupo formado pelo sexo masculino apresentou maior média, em comparação com o grupo formado pelo sexo feminino (feminino: $M=2,60 ; D P=0,82$; masculino: $M=2,79 ; D P=$ $0,73 ; t=2,23 ; p=0,03)$. Portanto, esses dados indicam maior autenticidade em mulheres e maior humor em homens.

Também não houve diferenças significativas para nenhum dos fatores da EAC em relação aos grupos formados pela situação laboral. Notou-se apenas que o grupo formado por empregados apresentou maior média na força de caráter Criatividade, em comparação com o grupo formado pelos desempregados (empregados: $M=2,60 ; \quad D P=0,76$; desempregados: $M=2,29 ; D P=0,90 ; t=2,68 ; p=0,01)$. A seguir, na Tabela 2 , são apresentados os dados da ANOVA e da prova de Tukey, que foram significativos nos fatores da EAC e nas forças de caráter da EFC, em relação à faixa etária.

Tabela 2. Análise de variância e prova de Tukey para os fatores da EAC e para as forças de caráter da EFC e na variável de grupo "faixa etária"

\begin{tabular}{|c|c|c|c|c|c|}
\hline \multirow[b]{2}{*}{ Fatores/Forças } & \multirow[b]{2}{*}{$F$} & \multirow[b]{2}{*}{$n$} & \multirow[t]{2}{*}{ Faixa Etária } & \multicolumn{2}{|c|}{ Subconjuntos } \\
\hline & & & & 1 & 2 \\
\hline \multirow[t]{4}{*}{ Preocupação $^{* * *}$} & 3,60 & 89 & De 30 a 37 anos & 3,91 & - \\
\hline & & 87 & De 38 a 47 anos & 3,91 & - \\
\hline & & 98 & De 48 a 71 anos & 4,00 & 4,00 \\
\hline & & 88 & De 18 a 29 anos & - & 4,18 \\
\hline \multirow[t]{4}{*}{ Criatividade" } & 3,11 & 88 & De 18 a 29 anos & 2,32 & - \\
\hline & & 87 & De 38 a 47 anos & 2,54 & 2,54 \\
\hline & & 89 & De 30 a 37 anos & 2,61 & 2,61 \\
\hline & & 98 & De 48 a 71 anos & - & 2,68 \\
\hline \multirow[t]{4}{*}{ Bravura* } & 3,70 & 88 & De 18 a 29 anos & 2,49 & - \\
\hline & & 87 & De 38 a 47 anos & 2,67 & 2,67 \\
\hline & & 89 & De 30 a 37 anos & 2,75 & 2,75 \\
\hline & & 98 & De 48 a 71 anos & - & 2,87 \\
\hline \multirow[t]{2}{*}{ Intel. Social* } & 3,40 & 88 & De 18 a 29 anos & 2,59 & - \\
\hline & & 89 & De 30 a 37 anos & 2,75 & 2,75 \\
\hline
\end{tabular}




\begin{tabular}{lllcc} 
& 98 & De 48 a 71 anos & 2,81 & 2,81 \\
& 87 & De 38 a 47 anos & - & 2,95 \\
\hline Imparcialidade* $^{3,14}$ & 88 & De 18 a 29 anos & 3,06 & - \\
& 89 & De 30 a 37 anos & 3,28 & 3,28 \\
& 87 & De 38 a 47 anos & 3,29 & 3,29 \\
& 98 & De 48 a 71 anos & - & 3,36 \\
\hline Bondade* $^{2,62}$ & 88 & De 18 a 29 anos & 2,78 & - \\
& 89 & De 30 a 37 anos & 2,93 & 2,93 \\
& 98 & De 48 a 71 anos & 2,93 & 2,93 \\
& 87 & De 38 a 47 anos & - & 3,05
\end{tabular}

Nota: $g l=3 ; " p<0,05 ; " p<0,01$.

Fonte: Elaborada pelos autores.

Conforme os dados descritos na Tabela 2, observou-se que o grupo da faixa etária de 18 a 29 anos apresentou uma média maior no fator Preocupação, diferenciando-se dos grupos de faixas etárias de 30 a 37 anos e de 38 a 47 anos. Esse resultado indicou que as pessoas mais jovens dessa amostra tenderam a pensar mais sobre seu futuro profissional do que as pessoas mais velhas.

Analisando as forças, os dados descritos mostram que o grupo da faixa etária de 48 a 71 anos, ou seja, os respondentes mais velhos, obteve uma média maior na força de caráter Criatividade, diferenciando-se do grupo da faixa etária de 18 a 29 anos, ou seja, o grupo dos mais jovens. O grupo que obteve a maior média na força Bravura também foi o grupo da faixa etária de 48 a 71 anos, diferenciando-se também do grupo da faixa etária mais jovem, ou seja, de 18 a 29 anos. Na força Inteligência Social, o grupo que obteve a maior média foi o grupo da faixa etária de 38 a 47 anos, e este também se diferenciou do grupo da faixa etária de 18 a 29 anos. Mais uma vez, o grupo dos mais velhos, ou seja, da faixa etária de 48 a 71 anos, obteve uma média maior na força Justiça e se diferenciou do grupo da faixa etária de 18 a 29 anos. E, por fim, o grupo da faixa etária de 38 a 47 anos obteve a maior média na força Humanidade, diferenciando-se mais uma vez do grupo dos mais jovens, com faixa etária de 18 a 29 anos. 
De maneira geral, ao analisar os resultados encontrados a partir da amostra do presente estudo, o grupo da faixa etária mais velha, dos 48 a 71 anos, diferencia-se na maioria dos casos do grupo da faixa etária mais jovem, ou seja, dos 18 a 29 anos, em três das cinco forças de caráter significativas: Criatividade, Bravura e Imparcialidade. E, a segunda faixa etária mais velha, ou seja, o grupo de 38 a 47 anos, diferencia-se também do grupo da faixa etária dos mais jovens, ou seja, dos 18 a 29 anos, em duas das cinco forças significativas: Inteligência Social e Bondade. Observa-se que, de qualquer maneira, os mais jovens, ou o grupo da faixa etária de 18 a 29 anos, diferenciam-se sempre com as menores médias, quando comparados aos mais velhos, significando possivelmente que a maturidade promove uma maior pontuação entre as forças de caráter.

A seguir, serão apresentados na Tabela 3 os dados da ANOVA e da prova de Tukey, que foram significativos nos fatores da EAC e nas forças de caráter da EFC, em relação à variável de grupo escolaridade. O grupo sem ensino superior foi formado pelo agrupamento de pessoas com ensino médio e com ensino superior incompleto, o grupo intitulado ensino superior completo aloca somente as pessoas com ensino superior completo, o grupo pósgraduação lato sensu contempla apenas as pessoas com especialização, e o grupo pósgraduação stricto sensu contempla pessoas com mestrado e doutorado.

Tabela 3. Análise de variância e prova de Tukey para os fatores da EAC e para as forças de caráter da EFC e na variável de grupo "escolaridade"

\begin{tabular}{lccccc}
\hline & & & Escolaridade & \multicolumn{2}{c}{ Subconjuntos } \\
\cline { 5 - 6 } Fatores/Forças & F & $n$ & & 1 & 2 \\
\hline Controle $^{*}$ & 2,86 & 63 & Sem ensino superior & 4,04 & - \\
& & 133 & Ensino superior completo & 4,17 & 4,17 \\
& 57 & Pós-graduação stricto sensu & 4,24 & 4,24 \\
& & 111 & Pós-graduação lato sensu & - & 4,30 \\
\hline Curiosidade $^{*}$ & 3,23 & 63 & Sem ensino superior & 3,82 & - \\
& & 133 & Ensino superior completo & 3,97 & 3,97 \\
& 57 & Pós-graduação stricto sensu & - & 4,11
\end{tabular}




\begin{tabular}{|c|c|c|c|c|c|}
\hline & & 111 & Pós-graduação lato sensu & - & 4,12 \\
\hline \multirow[t]{4}{*}{ Criatividade } & 2,35 & 63 & Sem ensino superior & 2,17 & - \\
\hline & & 133 & Ensino superior completo & - & 2,51 \\
\hline & & 111 & Pós-graduação lato sensu & - & 2,67 \\
\hline & & 57 & Pós-graduação stricto sensu & - & 2,72 \\
\hline \multirow[t]{4}{*}{ P. Crítico ${ }^{* *}$} & 7,38 & 63 & Sem ensino superior & 2,65 & - \\
\hline & & 133 & Ensino superior completo & - & 2,95 \\
\hline & & 111 & Pós-graduação lato sensu & - & 3,11 \\
\hline & & 57 & Pós-graduação stricto sensu & - & 3,14 \\
\hline \multirow[t]{4}{*}{ Sensatez } & 5,05 & 63 & Sem ensino superior & 2,35 & - \\
\hline & & 133 & Ensino superior completo & 2,51 & 2,51 \\
\hline & & 111 & Pós-graduação lato sensu & - & 2,73 \\
\hline & & 57 & Pós-graduação stricto sensu & - & 2,78 \\
\hline \multirow[t]{4}{*}{ Perseverança* } & 2,94 & 63 & Sem ensino superior & 2,88 & - \\
\hline & & 133 & Ensino superior completo & 3,04 & 3,04 \\
\hline & & 57 & Pós-graduação stricto sensu & 3,06 & 3,06 \\
\hline & & 111 & Pós-graduação lato sensu & - & 3,22 \\
\hline \multirow[t]{4}{*}{ Intel. Social $^{* *}$} & 6,14 & 63 & Sem ensino superior & 2,43 & - \\
\hline & & 133 & Ensino superior completo & - & 2,76 \\
\hline & & 111 & Pós-graduação lato sensu & - & 2,90 \\
\hline & & 57 & Pós-graduação stricto sensu & - & 2,90 \\
\hline \multirow[t]{4}{*}{ Imparcialidade } & 3,80 & 63 & Sem ensino superior & 3,02 & - \\
\hline & & 57 & Pós-graduação stricto sensu & 3,19 & 3,19 \\
\hline & & 133 & Ensino superior completo & 3,30 & 3,30 \\
\hline & & 111 & Pós-graduação lato sensu & - & 3,37 \\
\hline \multirow[t]{4}{*}{ Liderança $^{* * *}$} & 4,08 & 63 & Sem ensino superior & 2,45 & - \\
\hline & & 133 & Ensino superior completo & 2,65 & 2,65 \\
\hline & & 57 & Pós-graduação stricto sensu & - & 2,81 \\
\hline & & 111 & Pós-graduação lato sensu & - & 2,84 \\
\hline \multirow[t]{2}{*}{ Cidadania* } & 3,53 & 63 & Sem ensino superior & 2,72 & - \\
\hline & & 133 & Ensino superior completo & 3,00 & 3,00 \\
\hline
\end{tabular}




\begin{tabular}{ccccc} 
& 111 & Pós-graduação lato sensu & - & 3,01 \\
& 57 & Pós-graduação stricto sensu & - & 3,10 \\
\hline Amor Aprend. * & 63 & Sem ensino superior & 3,00 & - \\
& 133 & Ensino superior completo & 3,09 & 3,09 \\
& 57 & Pós-graduação stricto sensu & 3,13 & 3,13 \\
& 111 & Pós-graduação lato sensu & - & 3,31 \\
\hline
\end{tabular}

Nota: $\mathrm{gl}=3 ;{ }^{*} \mathrm{p}<0,05 ;{ }^{* *} \mathrm{p}<0,01$.

Fonte: Elaborada pelos autores.

Conforme mostra a Tabela 3, no fator Controle, o grupo de pessoas com pósgraduação lato sensu teve maior média, em comparação aos demais grupos, e diferenciouse em relação ao grupo de pessoas sem ensino superior. No fator Curiosidade, novamente o grupo com pós-graduação lato sensu obteve a maior média e diferenciou-se do grupo sem ensino superior. Em linhas gerais, as pessoas com pós-graduação, ou seja, com um maior nível de escolaridade, tenderam a apresentar maiores médias, em comparação às pessoas que não têm ensino superior.

Analisando as forças de caráter, o grupo formado por pessoas que têm pósgraduação stricto sensu obteve a maior média na força Criatividade, seguido dos grupos formados por pessoas que têm pós-graduação lato sensu e ensino superior completo. Esses grupos diferenciaram-se, respectivamente nessa ordem, do grupo formado pelas pessoas sem ensino superior. Seguindo essa mesma sequência, o grupo formado por pessoas com pós-graduação stricto sensu obteve a maior média na força Pensamento Crítico, seguido dos grupos formados por pessoas com graduação lato sensu e ensino superior completo.

$\mathrm{Na}$ força Sensatez, o grupo formado por pessoas com pós-graduação stricto sensu obteve a maior média, seguido do grupo formado pelas pessoas com graduação lato sensu, que, ao mesmo tempo, diferenciaram-se do grupo formado pelas pessoas sem ensino superior. Na força Perseverança, sobressai-se com a maior média o grupo formado pelas pessoas com pós-graduação lato sensu, que também se diferencia do grupo formado pelas pessoas sem ensino superior. Na força Inteligência Social, sobressaem-se igualmente com 
as maiores médias os grupos formados pelas pessoas que têm pós-graduação lato e stricto sensu, seguido pelo grupo formado por pessoas com ensino superior completo.

O grupo formado por pessoas com pós-graduação lato sensu obteve a maior média na força Imparcialidade, diferenciando-se do grupo formado pelas pessoas sem ensino superior. Na força Liderança, sobressai-se com a maior média o grupo formado por pessoas com pós-graduação lato sensu, seguido do grupo stricto sensu, sendo que esses dois diferenciam-se do grupo formado pelas pessoas sem ensino superior. Quanto à força Cidadania, o grupo formado pelas pessoas com pós-graduação stricto sensu obteve a maior média, seguido do grupo formado pelas pessoas com lato sensu, ambos se diferenciando do grupo sem ensino superior. Já na força Amor ao Aprendizado, o grupo formado por pessoas com pós-graduação lato sensu obteve a maior média e também se diferenciou do grupo formado pelas pessoas sem ensino superior.

Como panorama geral da Tabela 3 , as maiores médias sobre as nove forças de caráter apresentadas como significativas recaíram igualmente sobre os grupos formados pelas pessoas com pós-graduação lato e stricto sensu, sendo que no grupo de lato sensu as forças apontadas foram Perseverança, Inteligência Social, Imparcialidade, Liderança e Amor ao Aprendizado, e no grupo de stricto sensu as forças apontadas foram Criatividade, Pensamento Crítico, Sensatez, Trabalho em Equipe e, também, assim como no grupo de lato sensu, a força Inteligência Social. O grupo formado pelas pessoas com ensino superior não obteve as maiores médias, mas, juntamente com os grupos de pessoas com lato e stricto sensu, diferenciaram-se do grupo de pessoas sem ensino superior. Assim, a partir dos dados dessa amostra, percebe-se que pessoas com formação superior destacam-se das que não têm formação em pelo menos nove forças de caráter.

\section{Discussão}

Esta pesquisa justificou-se do ponto de vista prático, uma vez que os conceitos da Psicologia Positiva podem também auxiliar na compreensão dos processos de tomada de decisões de carreira de jovens e adultos e, nesse sentido, a Orientação Profissional e de 
Carreira também tem se dedicado a estudar as forças do funcionamento humano em prol de melhores caminhos e propósitos profissionais (Savickas, 1999). De acordo com o mesmo autor, a Orientação Profissional (OP) tem o objetivo de direcionar as pessoas em suas carreiras, compreender melhor as características das profissões, proporcionando, assim, autoconhecimento e o despertar de potencialidades até então desconhecidas. E foi nesse contexto de busca pela satisfação pessoal, valorização das forças do ser humano e orientação profissional e para a carreira que este estudo buscou evidências de validade da EFC (Noronha \& Barbosa, 2016).

Nesta seção, serão discutidos os resultados deste trabalho, iniciando com as correlações e, posteriormente, com as análises de variância. Conforme esperado, os dois construtos abordados se correlacionaram positivamente com magnitudes variando de fracas a fortes. O escore total da EFC correlacionado à EAC mostrou uma variação alta de 0,40 a 0,58 . Todas as correlações foram significativas, especialmente na dimensão Confiança, com um coeficiente de 0,58 , e na dimensão Controle, com um coeficiente de 0,54. Pode-se concluir que quanto maior a pontuação na EFC maior também a pontuação na EAC.

Para Savickas (2005; 2013), a Confiança, cuja correlação foi a mais evidente, corresponde à capacidade de acreditar em si mesmo para superar obstáculos, resolver problemas e atingir objetivos. Conforme mostram os resultados, a força mais fortemente correlacionada ao fator Confiança foi Amor ao Aprendizado. Para Peterson e Seligman (2004), essa força, definida como a motivação para aprender e dominar novas habilidades, é mais frequente quando há mais clareza por parte do indivíduo pelo que se gosta de estudar, de modo que tende a ser mais presente na maturidade. Pode-se entender que quanto mais o indivíduo tem dessa força, mais conhecimento tem e mais habilidades domina, e, assim, mais confiante e preparado se sente para atingir seus objetivos profissionais, característica esta relacionada ao fator Confiança.

Entre suas quatro forças abarcadas pela virtude Coragem, a que se destaca é a força Perseverança e, mais especificamente, esta também se destaca por sua segunda maior magnitude entre as 24 forças. Define-se Perseverança como sendo a capacidade de insistir, de forma não obsessiva, na busca de objetivos e de terminar o que se inicia, apesar dos 
obstáculos (Peterson \& Seligman, 2004). Tal resultado é coerente e indica que, assim como o fator Confiança, a força de caráter Perseverança é uma atitude e que, sem ela, impede o indivíduo de atingir seus objetivos. Já era hipótese deste estudo que as forças relacionadas à virtude Coragem estariam positivamente correlacionadas com o fator Confiança, resultado que corrobora a hipótese do trabalho. Essas forças, como já mencionado, permitem que o indivíduo enfrente as adversidades sem medo, tenha energia e seja legítimo com seus próprios sentimentos e ações.

Outro destaque é que todas as forças de caráter relacionadas à virtude Temperança correlacionaram-se mais fortemente ao fator Confiança e, finalmente, quatro das cinco forças relacionadas à virtude Transcendência correlacionaram-se mais fortemente ao fator Controle, com exceção da força Humor. Para Savickas (2005, 2013), a dimensão Controle significa responsabilidade incondicional, por criar sua própria história ou trajetória profissional e, ainda, o quanto os indivíduos sentem e acreditam que eles próprios são os responsáveis pela construção de suas carreiras. A dimensão Controle também abarca competências como autonomia, tomada de decisão, assertividade, lócus de controle interno e autodeterminação. Pode-se inferir que tal correlação positiva faz sentido, uma vez que as forças abarcadas na virtude Transcendência (Espiritualidade, por exemplo) sugerem competências essenciais e muito compatíveis com a dimensão Controle, por exemplo: apreciar a excelência no desempenho de várias habilidades, enxergar positivamente e ter um propósito maior e mais significativo (Peterson \& Seligman, 2004). Ainda, para Savickas (2005; 2013), a falta dessa dimensão é chamada de indecisão de carreira, sugerindo inabilidade para se fazer escolhas, o que pode estar intimamente correlacionado à falta da força Espiritualidade.

É válido lembrar que, para Park, Peterson e Seligman (2006), as virtudes são características humanas universais e essenciais para se resolver problemas e necessárias para a sobrevivência de qualquer ser humano; e as forças de caráter, por consequência, são elementos que definem as virtudes. Assim, por exemplo, para um indivíduo ter a virtude Transcendência, ele teria de primeiramente apresentar as forças Apreciação ao Belo, Gratidão, Esperança, Humor e Espiritualidade, ou pelo menos uma delas. De forma 
resumida, a maioria das forças de caráter, 16 mais especificamente (Curiosidade, Amor ao Aprendizado, Sensatez, Bravura, Perseverança, Autenticidade, Vitalidade, Bondade, Cidadania, Liderança, Imparcialidade, Autorregulação, Modéstia, Perdão, Prudência e Humor), correlacionou-se mais fortemente ao fator Confiança da EAC.

De modo geral e do ponto de vista psicométrico, é possível inferir que os resultados das correlações permitem interpretar dados em comum entre a Escala de Forças de Caráter e a Escala de Adaptabilidade de Carreira. A discussão a seguir será sobre as diferenças encontradas nos grupos classificados em sexo, situação laboral, faixa etária e escolaridade.

Entre os grupos formados por Sexo, Humor e Autenticidade, essas forças foram as que apresentaram diferenças significativas, sendo a primeira mais forte no grupo formado pelo sexo masculino e a segunda mais evidente no grupo formado pelo sexo feminino, corroborando a pesquisa mencionada no estudo normativo de Noronha e Barbosa (2016). Park et al. (2006) também revelam em pesquisa realizada em 54 países, incluindo o Brasil, as forças de caráter mais e menos destacadas. As mais destacadas incluíram as forças Autenticidade e Humor.

Uma importante contribuição desta pesquisa foi o que se constatou quanto à situação laboral. Nota-se que o grupo formado por empregados apresentou maior média na força de caráter Criatividade, em comparação com o grupo formado pelos desempregados, sugerindo que a capacidade de inovar e estar aberto a novas experiências (Peterson \& Seligman, 2004) são fundamentais para aqueles que desejam se manter empregados. As mudanças no mundo organizacional têm exigido que os trabalhadores desenvolvam habilidades e competências que se diferenciem substancialmente das habilidades e competências requeridas pelas ocupações do século $X X$, que oferecia empregos e organizações estáveis. Mas, com a revolução digital (Hodges, 2004) e com as transformações sociodemográficas (Drucker, 1992), por exemplo, há novos paradigmas quanto aos cargos permanentes, sendo estes substituídos lentamente por projetos de tempo limitado ou temporários (Kalleberg, Reskin \& Hudson, 2000). No cenário atual, quando da distribuição da pesquisa, o Brasil passa por sua maior crise financeira e política da história, o que levou ao crescimento do desemprego e, assim, muitos brasileiros foram 
obrigados a enxergar oportunidades de negócios e empreender, sugestionando, dessa forma, mais uma vez a necessidade do desenvolvimento e aplicação da força Criatividade.

Quanto à faixa etária, observou-se que o grupo da faixa etária de 18 a 29 anos apresentou uma média maior no fator Preocupação, diferenciando-se dos grupos de faixas etárias de 30 a 37 anos e de 38 a 47 anos. Esse resultado infere que as pessoas mais jovens costumam pensar mais sobre seu futuro profissional do que as pessoas mais velhas, que, ao contrário dos mais jovens, apresentam as maiores médias nas forças Criatividade, Bravura, Imparcialidade, Bondade e Inteligência Social, significando possivelmente que a maturidade promove uma maior pontuação entre as forças de caráter.

De acordo com a teoria de construção de carreira de Savickas (2002), a adaptabilidade tem quatro pilares, representados pela Estrutura (papéis sociais), Estratégias (competências comportamentais), História (significado e propósito ao trabalho) e Estilo (diferenças individuais). Visto que os jovens ainda estão em construção desses quatro pilares, seria mais assertivo inferir que pessoas mais velhas estão à frente em todos os sentidos: maior vivência de papéis, mais tempo no desenvolvimento de competências, mais história de vida e valores mais alinhados aos seus propósitos e podem, por meio de seus sucessos e fracassos, remodelar de forma bem articulada suas carreiras.

Nota-se também por meio dos resultados que as forças abarcadas nas virtudes Sabedoria e Conhecimento e Coragem são as mais evidentes e associadas ao fator Confiança, sugerindo também que o fator Confiança pode estar mais relacionado à fase de maior maturidade do indivíduo (acima de 38 anos) e o fator Preocupação à fase de menor maturidade (de 18 a 29 anos de idade), fase essa mais comum de preparação para o futuro. A seguir será apresentado outra contribuição importante e única desta pesquisa: a discussão dos dados da ANOVA e da prova de Tukey, que foram significativos nos fatores da EAC, em relação à variável de grupo escolaridade.

Constata-se, pelos resultados, que pessoas com formação superior, lato e/ou stricto sensu destacam-se das que não têm formação em pelo menos nove forças de caráter: Perseverança, Inteligência Social, Imparcialidade, Liderança, Amor ao Aprendizado, Criatividade, Pensamento Crítico, Sensatez, Cidadania e Inteligência Social. De maneira 
generalizada, pessoas com mais idade têm naturalmente maior nível de escolaridade. Logo, pode-se inferir que, com a maturidade, associada a um maior nível de conhecimento, os indivíduos têm um número maior de forças de caráter desenvolvidas, em sua grande maioria abarcada nas virtudes Sabedoria e Conhecimento e Justiça.

\section{Considerações finais}

Acredita-se que os objetivos propostos nesta pesquisa foram alcançados: encontrar evidências de validade para a Escala de Forças de Caráter, correlacionando-a com a Escala de Adaptabilidade de Carreira e variáveis externas. Do ponto de vista científico, este estudo serve como contribuição de mais uma evidência de validade para a Escala de Forças de Caráter, especialmente pela escassez em pesquisas e por não encontrá-las no contexto da orientação para a carreira. Este estudo também gerou contribuições importantes e inéditas por meio dos resultados das correlações entre as forças e as variáveis empregados e desempregados e entre as forças e a variável escolaridade. Ademais, do ponto de vista prático, há reflexões importantes a serem consideradas, pois os instrumentos podem também servir como formas de autoconhecimento e autogestão para os processos de orientação de carreira e/ou coaching e, ainda, podem ser aplicados como atividades da área de Treinamento e Desenvolvimento e Processos Educativos, pois conhecendo melhor suas potencialidades o indivíduo pode compreender e relacioná-las melhor com as características das profissões e, assim, reconhecer os valores e propósitos que o conduzirão à autorrealização.

Contudo, o campo de pesquisa está longe de se esgotar e foi permeada de algumas limitações. A amostra de participantes, por exemplo, não teve, por conveniência, o mesmo número de homens e mulheres, empregados e desempregados. A localização dos respondentes esteve longe de abranger todo o território nacional e limitou-se basicamente no estado de São Paulo (região mais desenvolvida do país) e no estado do Paraná. Embora meticulosamente analisadas, as hipóteses poderiam ter sido mais bem estruturadas, por 
exemplo, poderia se hipotetizar as magnitudes das forças e não apenas quais teriam correlações positivas.

Em especial, por conta da reforma trabalhista, recentemente aprovada, pode-se, para futuros estudos, avaliar as variáveis relacionadas, por exemplo, às pessoas que estão trabalhando sob o regime da CLT com funcionários públicos e autônomos. Também se pode correlacionar as variáveis com pessoas que trabalham ou não na sua área de formação e por tempo de experiência no mercado, ou seja, por meio de grupos que possuem no mínimo 6 meses de experiência a 2 anos, de 3 a 5 anos de experiência no mercado de trabalho, de 6 a 9 anos, de 10 a 15 anos, de 16 a 20 anos, de 21 a 25 anos e com aqueles que têm mais de 25 anos de experiência no mercado de trabalho.

\section{Referências}

Balbinotti, M. A. A. (2003). A noção transcultural de maturidade vocacional na teoria de Donald Super. Psicologia: Reflexão e Crítica, 16(3), 561-473. Recuperado de http:// www.scielo.br/pdf/\%0D/prc/v16n3/v16n3a05.pdf.

Browning, L., Ryan, C. S., Greenberg, M. S., \& Rolniak, S. (2006). Effects of Cognitive Adaptation on the Expectation-Burnout Relationship among Nurses. Journal of Behavioral Medicine, 29(2), 139-150. doi:10.1007/s10865-005-9028-1.

Buyukgoze-Kavas, A. (2015). Predicting Career Adaptability from Positive Psychological Traits. The Career Development Quartely, 64, 114-125. doi: $10.1002 /$ cdq. 12045 .

Cameron, K. S., \& Spreitzer, G. M. (2003). The Oxford Handbook of Positive Organizational Scholarship. New York: Oxford University Press.

Cameron, K. S., Dutton, J. E., \& Quinn, R. E. (2003). Foundation of Positive Organizational Scholarship. In K. S. Cameron, E. J. Dutton, J. E. \& R. E. Quinn (Eds.). Positive 
Organizational Scholarship: Foundation of a New Discipline (pp. 3-13). San Francisco: Berret-Koehler.

Cohen, J. (1992). A Power Primer. Psychological Bulletin, 112(1). 155-159. doi: $10.1037 / 0033-2909.112 .1 .155$.

Drucker, P. (1992). Administrando para o futuro: os anos 90 e a virada do século (2a ed.). São Paulo: Pioneira.

Hirschi, A. (2014). Hope as a Resource for Self-Directed Career Management: Investigating Mediating Effects on Proactive Career Behaviors and Life and Job Satisfaction. Journal of Happiness Studies, 15, 1495-1512. doi:10.1007/s10902-013-9488-x.

Hodges, A. (2004). Alan Turing: an Introductory Biography. In C. Teuscher (Ed.). Alan Turing: Life and Legacy of a Great Thinker (2a ed., pp. 3-8). Springer: Berlin.

Johnston, C. S., Broonen, J. P., Stauffer, S. D., Hamtiaux, A., Poyaud, J., Zecca, G., Houssemand, C., \& Rossier, J. (2013). Validation of an Adapted French Form of the Career Adapt-Abilities Scale in four Francophone Countries. Journal of Vocational Behavior, 83, 1-10. doi: 10.1016/j.jvb.2013.02.002.

Johnston, C. S., Luciano, E. C., Maggiori, C., Ruch, W., \& Rossier, J. (2013). Validation of the German Version of the Career Adapt-Abilities Scale and its Relation to Orientations to Happiness and Work Stress. Journal of Vocational Behavior, 83(3), 295-304. doi: 10.1016/j.jvb.2013.06.002.

Kalleberg, A. L., Reskin, B. F., \& Hudson, K. (2000). Bad Jobs in America: Standard and NonStandard Employment Relations and Job Quality in the United States. American Sociological Review, 65(2), 256-278. Retrieved from https://www.jstor.org/stable/2657440?seq=1\#page_scan_tab_contents. 
Littman-Ovadia, H., Lavy, S., \& Boiman-Meshita, M. (2017). When Theory and Research Collide: Examining Correlates of Signature Strengths Use at Work. Journal of Happiness Studies, 18(2), 527-548. doi: 10.1007/s10902-016-9739-8.

Luthans, F. (2002). Positive Organizational Behavior: Developing and Managing Psychological Stregths. Academy of Management Executive, 16, 57-72. doi: $10.5465 /$ ame.2002.6640181.

Maggiori, C., Johnston, C. S., Krings, F., Massaoudi, K., \& Rossier, J. (2013). The Role of Career Adaptability and Conditions on General and Professional Well-Being. Journal of Vocational Behavior, 83(3), 437-449. doi: 10.1016/j.jvb.2013.07.001.

Noronha, A. P. P., \& Barbosa, A. J. G. (2016). Forças e virtudes: escala de forças de caráter. In C. S. Hutz. Avaliação em Psicologia Positiva: técnicas e medidas. São Paulo: Hogrefre.

Ohme, M., \& Zacher, H. (2015). Job Performance Ratings: The Relative Importance of Mental Ability, Conscientiousness, and Career Adaptability. Journal of Vocational Behavior, 87. doi: $10.1016 /$ j.jvb.2015.01.003.

Park, N., \& Peterson, C. (2009). Character Strengths: Research and Practice. Journal of College and Character, 10(4), 1-10. doi: 10.2202/1940-1639.1042.

Park, N., Peterson, C., \& Seligman, M. E. P. (2006). Character Strengths in Fifty-Four Nations and the Fifty US States. Journal of Positive Psychology, 1, 118- 129. doi: $10.1080 / 17439760600619567$.

Peterson, C., \& Seligman M. E. P. (2004). Character Strenghts and Virtues: a Handbook and Classification. Washington, DC: American Psychological Association, Oxford University Press.

Pouyaud, J., Vignoli, E., Dosnon O., \& Lallemand, N. (2012). Career Adapt-Abilities ScaleFrance Form: Psychometric Properties and Relationships to Anxiety and Motivation. Journal of Vocational Behavior, 80(3), 692-697. doi: 10.1016/j.jvb.2012.01.021. 
Savickas, M. L. (1999). The Psychology of Interests. In M. L. Savickas \& A. R. Spokane (Eds.). Vocational Interests: Meaning, Measurement and Counseling Use. Palo Alto, CA: Davies-Black, 19-56.

Savickas, M. L. (2002). Career Construction: a Developmental Theory of Vocational Behavior. In D. Brown \& Associates (Eds.). Career Choice and Development (4a ed., pp. 149205). San Francisco: Jossey Bass.

Savickas, M. L. (2005). The Theory and Practice of Career Construction. In S. D. Brown \& R. W. Lent (Eds.). Career Development and Counseling: Putting Theory and Research to Work (pp. 42-70). Hoboken: Wiley.

Savickas, M. L. (2013). The Theory and Practice of Career Construction. In S. D. Brown \& R. W. Lent (Eds.). Career Development and Counseling: Putting Theory and Research to Work (2a ed., pp. 147-183). Hoboken: Wiley.

Savickas, M. L., \& Porfeli, E. J. (2012). The Career Adapt-Abilities Scale: Construction, Reliability, and Measurement Equivalence Across 13 Countries. Journal of Vocational Behavior, 80(3), 661-673. doi: 10.1016/j.jvb.2012.01.011.

Seligman, M. E. P., \& Csikszentmihalyi, M. (2000). Positive Psychology: an Introduction. American Psychologist, 55(1), 5-14. doi: 10.1037/0003-066X.55.1.5.

Snyder, C. R. (2002). Hope Theory: Rainbows in the Mind. Psychological Inquiry, 13, 249275. doi: 10.1207/S153227965PLI1304-01.

Super, D. W. (1980). A life-Span, Life-Space Approach to Career Development. Journal of Vocational Behavior, 16(3), 282-298. doi: 10.1016/0001-879(80)90056-1.

Teixeira, M. A. P., Bardagi, M. P., Lassance, M. C. P., Magalhães, M. O., \& Duarte, M. E. (2012). Career Adapt-Abilities Scale Brazilian Form: Psychometric Properties and Relationships to Personality. Journal of Vocational Behavior, 80(3), 680-685. doi: 10.1016/j.jvb.2012.01.007. 
Van Meter, K. M. (1990). Methodological and Design Issues: Techniques for Assessing the Representatives of Snowball Samples. In E.Y. Lambert. The Collection and Interpretation of Data from Hidden Populations. Washington: National Institute on Drug Abuse.

Van Vianen, Klehe, A. E. M., Koen, U. C., J., \& Dries, N. (2012). Career Adapt-Abilities ScaleNetherlands Form: Psychometric Properties and Relationships to Ability, Personality, and Regulatory Focus. Journal of Vocational Behavior, 80(3), 716-724. doi: 10.1016/j.jvb.2012.01.002.

Wanberg, C. R., \& Banas, J. T. (2000). Predictors and Outcomes of Openness to Changes in a Reorganizing Workplace. Journal of Applied Psychology, 85, 132-142. doi: 10.1037/0021-9010.85.1.132.

Recebido em: 19/6/2018

Aprovado em: 26/11/2018 